\title{
Exacerbated inflammatory responses in transgenic mice expressing an inhibitor of apoptosis protein (OpIAP)
}

\author{
MS Robles ${ }^{\star, 1}$, E Leonardo ${ }^{1}$, LM Criado ${ }^{1}$, M Izquierdo $^{2}$ and \\ C Martínez- $\mathrm{A}^{1}$ \\ 1 Department of Immunology and Oncology, Centro Nacional de Biotecnología/ \\ CSIC, UAM Campus de Cantoblanco, E-28049 Madrid, Spain \\ 2 Instituto de Biología y Genética Molecular CSIC-Universidad de Valladolid, \\ Facultad de Medicina, Ramón y Cajal 7, E-47005 Valladolid, Spain \\ * Corresponding author: MS Robles. Tel: + 34-91-585-4537; \\ Fax: + 34-91-372-0493; E-mail: msrobles@ cnb.uam.es
}

Received 14.10.02; revised 31.3.03; accepted 21.5.03

Edited by G Melino

\begin{abstract}
Members of the inhibitor of apoptosis protein family are involved not only in suppressing apoptosis, but also in signal transduction, cell division, and are associated with some types of cancers. Here we show that transgenic expression of the inhibitor of apoptosis protein OpIAP in murine T lymphocytes leads to a significant increase in T-cell receptor-induced cell activation, proliferation and cytokine production. Transgenic T lymphocytes expressing OpIAP have a lower proliferation threshold in response to T-cell receptor stimulation. Unstimulated OpIAP transgenic $T$ lymphocytes show elevated nuclear levels of NF- $\kappa$ B transcription factor that increase after in vivo antigen peptide treatment. OpIAP transgenic animals present an exacerbated inflammatory response in an experimental contact hypersensitivity model, suggesting increased T-cell activation in vivo. These data indicate a new role for the inhibitor of apoptosis proteins in T-lymphocyte activation and proliferation.

Cell Death and Differentiation (2003) 10, 1226-1233. doi:10.1038/ sj.cdd. 4401297
\end{abstract}

Keywords: inflammation; T lymphocyte; proliferation; transcription factors; inhibitor of apoptosis

Abbreviations: BIR, baculovirus IAP repeat; BRUCE, BIR repeat containing ubiquitin-conjugating enzyme; CARD, caspase-recruitment domain; CHS, contact hypersensitivity; DNBS, dinitrobenzene sulfonic acid; DNFB, 2,4-dinitrofluorobenzene; IAP, inhibitor of apoptosis proteins; IKK, I $\kappa \mathrm{B}$ kinase complex; MEKK, mitogen-activated protein/ERK kinase kinase; OpIAP, IAP generated from the Orgyia pseudotsugata nuclear polyhedrosis virus; tg, transgenic; wt, wild type

\section{Introduction}

The inhibitor of apoptosis proteins (IAPs) constitute a family of cell death suppressors, conserved throughout evolution, which are found in many species from virus to mammals. ${ }^{1}$
The IAPs are characterized by the existence of at least one copy of a common baculovirus IAP repeat (BIR) domain, which is essential for their antiapoptotic properties. ${ }^{2}$ Most IAPs also contain a characteristic zinc finger motif, called RING, located at the carboxy-terminus. ${ }^{2}$ The RING domain of many IAPs is described to have ubiquitin-ligase activity and to interact with ubiquitin complex components. ${ }^{3,4}$ Furthermore, the IAP BIR repeat containing ubiquitin-conjugating enzyme (BRUCE) has an additional domain with ubiquitin-conjugating enzyme (E2) activity. ${ }^{5}$ Although IAPs were initially discovered due to their ability to suppress apoptosis, other cellular functions have been demonstrated for certain members of this family. Some IAPs induce activation of the transcription factor $\mathrm{NF}-\kappa \mathrm{B}$ by increasing its nuclear levels. ${ }^{6-10}$

The baculoviral OpIAP was one of the first IAP family members identified; it shares the characteristic structural composition with cellular counterparts such as XIAP, c-IAP1 and C-IAP2: two BIR motifs located in the amino-terminal region and a RING zinc finger in the carboxy-terminus of the protein. $^{2}$ Although OpIAP was originally described as a caspase inhibitor in insect cells, ${ }^{11}$ it also inhibits apoptosis when expressed in mammalian cells. ${ }^{8,12}$ We recently reported that, in addition to blocking apoptosis, OpIAP expression in developing thymocytes also increases NF- $\kappa$ B nuclear levels, which seems to be coupled to the enhanced activation and proliferative response of transgenic (tg) thymocytes. ${ }^{8}$

$T$ lymphocytes are necessary for generation and regulation of the immune response. T-cell stimulation through the T-cell receptor (TCR) triggers several signaling pathways that ultimately lead to the activation of certain transcription factors, including members of the NF- $\kappa \mathrm{B}$ family. NF- $\kappa \mathrm{B}$ is a key regulatory element of immune and inflammatory responses ${ }^{13,14}$ and activates transcription of genes that encode proteins required for the immune response, such as immune receptors, inflammatory cytokines and chemokines. ${ }^{15}$

In resting $\mathrm{T}$ cells, NF- $\kappa \mathrm{B}$ is maintained inactive, bound to $I_{\kappa} \mathrm{B}$ proteins including $\mathrm{I} \kappa \mathrm{B} \alpha$, a major $\mathrm{NF}-\kappa \mathrm{B}$ inhibitor in lymphocytes. ${ }^{16}$ Many biological factors, such as TCR triggering, induce $I_{\kappa} \mathrm{B} \alpha$ phosphorylation by the $I_{\kappa} \mathrm{B}$ kinase (IKK) complex, followed by polyubiquitination and proteosomedependent degradation. NF- $\kappa$ B is then free to bind to DNA and activate transcription of its target genes. ${ }^{13}$

Previous work showed that the expression of some IAPs is associated with increased nuclear levels of NF- $\kappa$ B via an unknown pathway. ${ }^{7-9}$ Since NF- $\kappa$ B is an essential regulator of the $\mathrm{T}$-cell response, we used $\mathrm{T}$-lineage-specific tg expression in mice to study the effects of the IAP protein OpIAP on Tlymphocyte function and physiology. The data illustrate a new role for IAPs in T-cell responses; OpIAP enhances Tlymphocyte activation, proliferation and cytokine production probably by increasing nuclear NF- $\kappa \mathrm{B}$ levels. Increased in vivo $\mathrm{T}$-cell activation is also demonstrated by an exacerbated inflammatory response in OpIAP tg mice. 
a

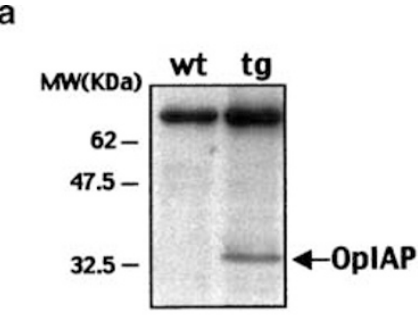

c
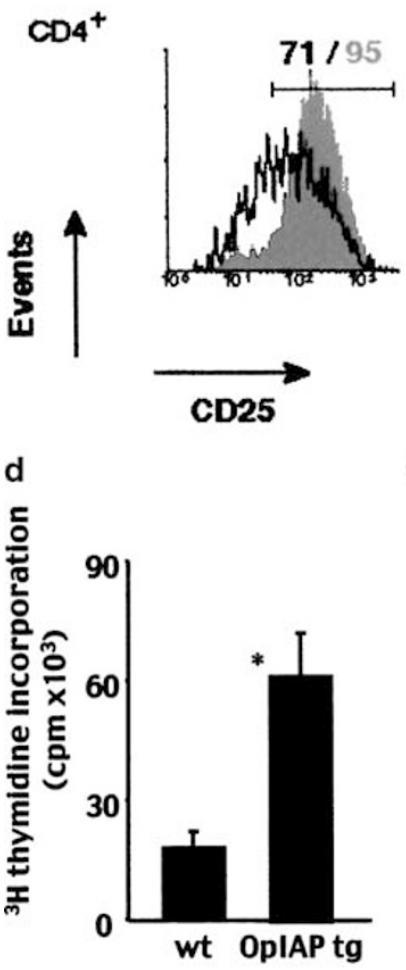

b

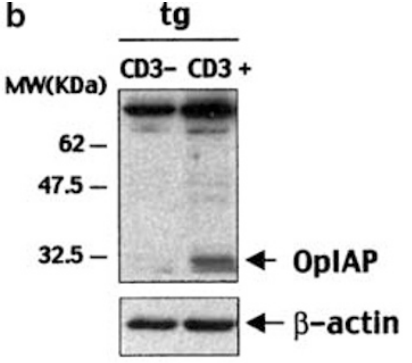

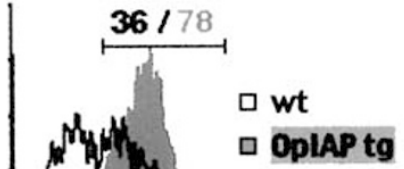

e wt \&

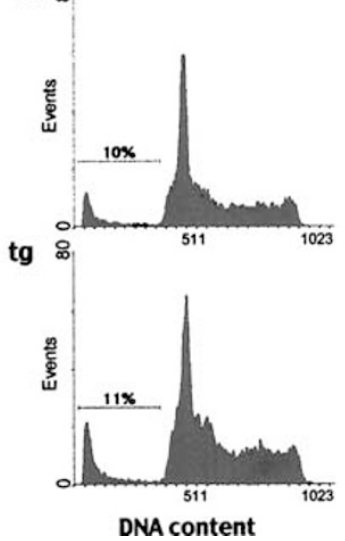

f

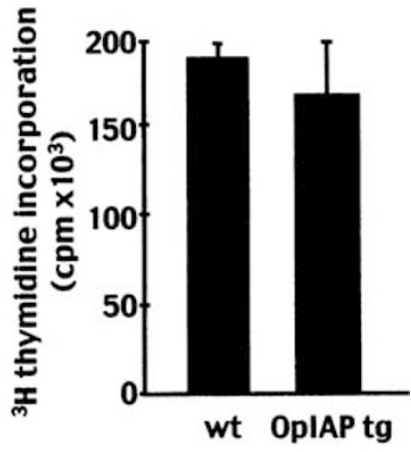

Figure 1 Increased CD3-mediated activation and proliferative responses of OpIAP tg T lymphocytes. (a) Analysis of OpIAP protein levels in lymph node extracts from OpIAP tg and control wt mice, detected by Western blot using polyclonal anti-OpIAP antiserum. (b) OpIAP levels in CD3-negative and -positive cells purified by FACS from the lymph nodes of OpIAP tg mice. (c) Percentage of CD25-positive cells in CD3-triggered mature T lymphocytes (gated on live CD8 ${ }^{+}$or CD4 ${ }^{+}$) from wt (white histograms) and OpIAP tg (gray histograms) mice $24 \mathrm{~h}$ after stimulation. Basal expression was undetectable in unstimulated cells ( $\leq 5 \%)$ and is not shown. (d) Tlymphocyte proliferation measured as ${ }^{3}[\mathrm{H}]$ thymidine incorporation after $48 \mathrm{~h}$ cell culture in the presence of plastic-bound anti-CD3 antibody $(5 \mu \mathrm{g} / \mathrm{ml})$. The asterisk indicates statistical significance between bars ( $P=0.0032$; Student's two-tailed $t$-test). (e) The graphs show the DNA content of CD3-positive cells after PI staining from wt (top) and OpIAP tg (bottom) total lymph node cultures after $48 \mathrm{~h}$ anti-CD3 stimulation. Bars and the numbers indicate the percentage of dead cells (sub-G $/ G_{1}$ DNA content) in the proliferation cell cultures shown in d. (f) Bars show ${ }^{3}[\mathrm{H}]$ thymidine incorporation of wt and OplAP tg T-lymphocyte cultures $48 \mathrm{~h}$ after PMA plus ionomycin stimulation. The data in $(\mathbf{d}, \mathbf{f})$ represent the mean \pm S.D. of values for wt $(n=3)$ and OplAP tg mice $(n=3)$. No specific proliferation $(\leq 500 \mathrm{cpm})$ was detected in unstimulated cultures

\section{Results}

\section{OpIAP expression in peripheral T lymphocytes enhances TCR-induced activation and proliferation}

Previously we reported that OpIAP expression in developing thymocytes enhances TCR-triggered proliferation and activation of these cells. To study whether OpIAP also affects TCRmediated responses in mature $T$ cells, we used tg mice expressing OpIAP under the control of the p56lck proximal promoter. ${ }^{8}$ Western blot analysis of cytosolic extracts revealed the presence of OpIAP in peripheral T cells (Figure $1 a$ and $b$ ). OpIAP tg mice showed no alteration in total cell number or T-lymphocyte repertoire in lymph nodes compared to their wild-type (wt) counterparts. Similarly, no differences were found in the total cell number or T-lymphocyte percentages in lymph nodes from OpIAP/F5TCR double tg animals, in which the majority of T lymphocytes are CD8 ${ }^{+17}$ (Table 1). We studied the effect of OpIAP expression on T-lymphocyte activation and proliferative responses following anti-CD3/TCR triggering. At $24 \mathrm{~h}$ after anti-CD3 stimulation, OpIAP tg T lymphocytes expressed much higher surface levels of the CD25 activation marker compared to wt T cells 
Table 1 Total cell numbers and percentages of $\mathrm{CD}^{+}$and $\mathrm{CD} 4^{+} \mathrm{T}$ lymphocytes in lymph nodes from wt and OpIAP tg mice on a wt (left) and on a F5TCR (right) background

F5TCR

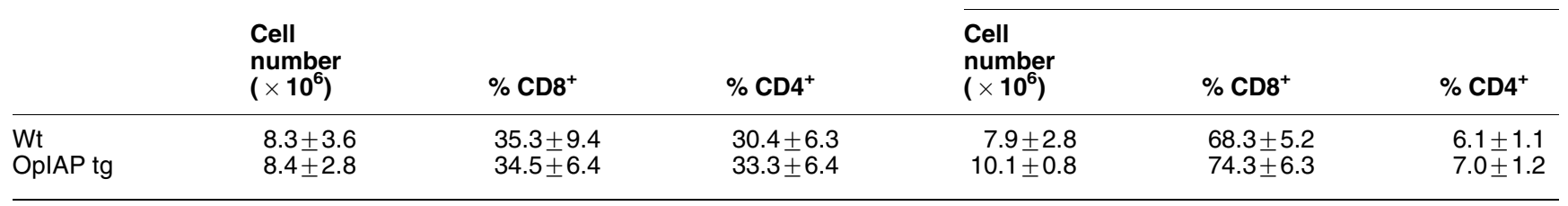

Numbers correspond to the average \pm S.D. for values of wt $(n=11)$, OpIAP $(n=12)$, F5TCR $(n=3)$ and F5TCR/OpIAP $(n=4)$ mice

(Figure 1c). Although anti-CD3-induced CD25 expression was higher in both $\mathrm{CD}^{+}$and $\mathrm{CD}^{+}$tg T-lymphocyte subpopulations, more notable differences were found between $\mathrm{tg}$ and wt mice in $\mathrm{CD}^{+} \mathrm{T}$ cells (Figure 1c). The percentage of viable cells was similar in cultures from wt and OpIAP tg total lymph node cells $24 \mathrm{~h}$ after anti-CD3 stimulation (not shown)

Since activation precedes T-cell proliferation, we tested anti-CD3-induced proliferation in OpIAP $\mathrm{tg}$ compared to wt T lymphocytes. At $48 \mathrm{~h}$ after anti-CD3 triggering, tg T lymphocytes expressing OpIAP showed a three-fold greater proliferative response compared to wt $\mathrm{T}$ cells, as measured by ${ }^{3}[\mathrm{H}]$ thymidine incorporation (Figure $1 \mathrm{~d}$ ). Cell cycle analysis by $\mathrm{PI}$ staining showed that the percentage of cell death in the CD3-positive cell population (subG ${ }_{0} / G_{1}$ DNA content) was similar in wt and OpIAP cell cultures (Figure 1e). The increased proliferation exhibited by OpIAP T-cell cultures after CD3 stimulation is thus probably due to a greater ability to proliferate rather than increased survival. To determine whether the OpIAP effect on T-lymphocyte proliferation is specific to the TCR/CD3 signaling pathway, we analyzed T-lymphocyte proliferation induced by PMA plus ionomycin. Thymidine incorporation values at $48 \mathrm{~h}$ after treatment were similar in T-lymphocyte cultures from wt and OpIAP tg mice (Figure 1f). These data indicate that OpIAP increases anti-CD3-induced T-lymphocyte activation as well as proliferation specifically associated with TCR/CD3 triggering.

\section{OpIAP tg T lymphocytes have a lower proliferation threshold}

We determined the proliferative response of wt and OpIAP tg $T$ lymphocytes to suboptimal concentrations of anti-CD3 antibody. OpIAP $\operatorname{tg} \mathrm{T}$ lymphocytes proliferated at an anti-CD3 dose $(0.6 \mu \mathrm{g} / \mathrm{ml})$ that was insufficient to induce wt T-cell proliferation (Figure 2). At a higher anti-CD3 dose $(1.25 \mu \mathrm{g} /$ $\mathrm{ml})$, wt T cells showed marginal proliferation, whereas OpIAP $\operatorname{tg}$ T-lymphocyte proliferation values were nearly 10-fold higher than those of wt T cells. No differences were found in anti-CD3-induced cell death between wt and OpIAP tg Tlymphocyte cultures (not shown). OpIAP tg T lymphocytes thus exhibit a lower proliferation threshold than wt $\mathrm{T}$ cells, as well as greatly increased proliferation at nonlimiting doses of anti-CD3 antibody.

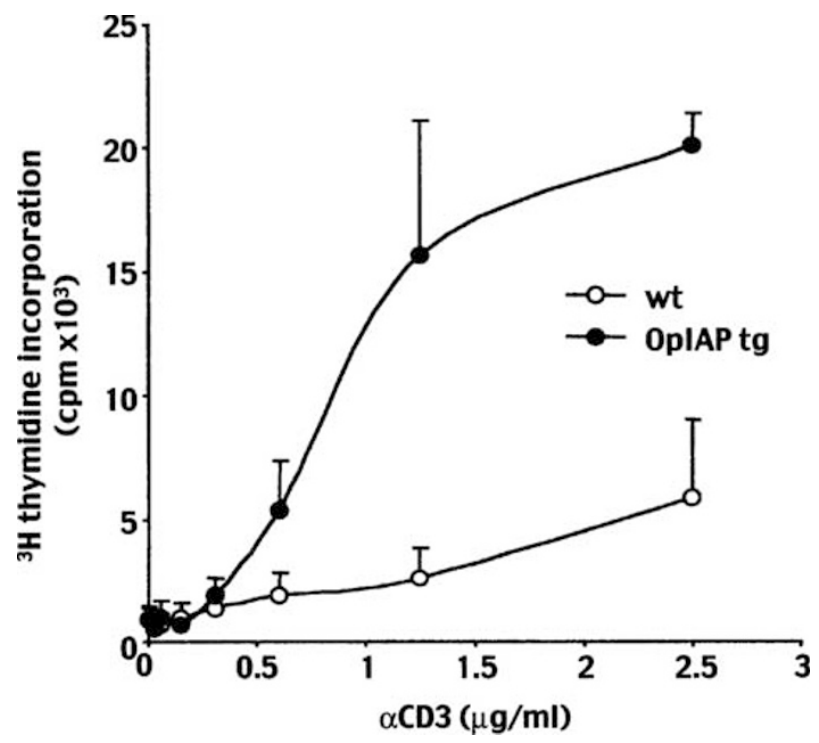

Figure 2 Reduced proliferation threshold of $\operatorname{tg} T$ lymphocytes. Proliferation values for wt (open symbols) and OpIAP tg (closed symbols) T lymphocytes $48 \mathrm{~h}$ after stimulation with anti-CD3 antibody. Results are shown as mean and standard deviation (S.D.) of triplicate samples. The result is representative of three independent experiments

\section{Increased cytokine production by OpIAP tg T lymphocytes}

To estimate the degree of T-cell activation, we analyzed cytokine production by wt and OpIAP tg $\mathrm{T}$ lymphocytes following anti-CD3 stimulation. At $24 \mathrm{~h}$ poststimulation, fourfold higher IL-2 levels were detected in OpIAP T-lymphocyte culture supernatants compared to those of wt cells (Figure $3 a$ ). This difference was reduced after $48 \mathrm{~h}$, probably due to cytokine accumulation in the supernatants; IL-2 levels nonetheless remained higher in OpIAP tg T-cell cultures (Figure 3a). IFN- $\gamma$, which is also produced after T-cell activation, was detected at significantly higher levels (nearly 100-fold) in OplAP tg T-lymphocyte supernatants than in wt T cell cultures at $24 \mathrm{~h}$ after anti-CD3 stimulation (Figure $3 \mathrm{a}$ ). Similarly to IL-2, these differences were reduced after $48 \mathrm{~h}$ of culture, although IFN- $\gamma$ levels in OpIAP T-cell supernatants remained much higher than those observed in wt cultures (Figure 3a). At $48 \mathrm{~h}$ after CD3 triggering, TNF $\alpha$, another cytokine involved in $\mathrm{T}$-cell responses, was detected only slightly higher in $\operatorname{tg} \mathrm{T}$-cell culture supernatants than in those 

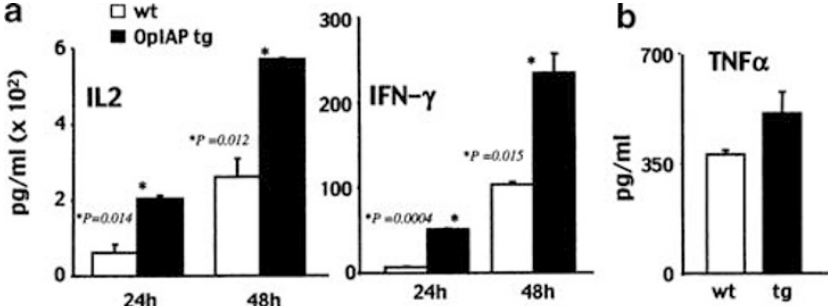

C

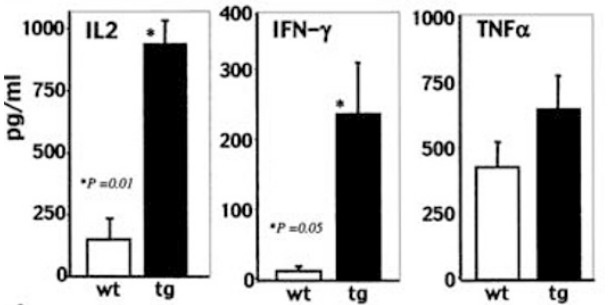

d

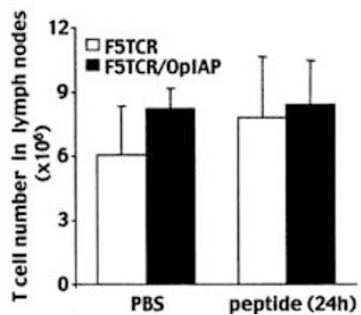

Figure 3 Enhanced in vitro and in vivo cytokine production by OpIAP tg T lymphocytes after anti-CD3/TCR triggering. (a) IL-2 and IFN- $\gamma$ levels in Tlymphocyte culture supernatants measured by ELISA at 24 and $48 \mathrm{~h}$ after incubation on anti-CD3-coated plates. (b) TNF $\alpha$ supernatant levels in the same cultures measured $48 \mathrm{~h}$ after stimulation. The graphs represent cytokine concentration (mean \pm S.D.) for wt ( $n=3$; open bars) and OpIAP ( $n=3$; closed bars) tg T-lymphocyte cultures. (c) Serum levels of IL-2, IFN- $\gamma$ and TNF $\alpha$ in F5TCR (wt; $n=7$; open bars) and F5TCR/OplAP tg mice (tg, $n=7$; closed bars), measured 90 min after antigenic peptide injection. Cytokine levels were below the detection limit $(\leq 15 \mathrm{pg} / \mathrm{ml})$ in unstimulated cultures and in untreated mice. (d) Number of viable T lymphocytes of F5TCR $(n=3)$ and F5TCR/OpIAP $\operatorname{tg}(n=4)$ mice injected with the antigenic peptide or with PBS. The asterisks indicate the $P$ value (Student's two-tailed $t$-test) for groups of data statistically significant between wt and OpIAP tg mice

from wt T cells (Figure 3b). Since cell survival is not enhanced in OpIAP cell cultures stimulated with anti-CD3 (see Figure 1f), the increased cytokine production in ex vivo anti-CD3activated OpIAP T lymphocytes appears to be due to enhanced T-cell activation and not to increased numbers of T cells producing cytokines.

In vivo cytokine production in response to T-cell activation was also tested in OplAP-expressing mice. We used the F5TCR $t g$ mouse model, in which a tg TCR that recognizes a specific influenza virus nucleoprotein peptide is expressed in most T cells. ${ }^{18}$ Injection of the antigenic peptide into F5TCR mice leads to T-lymphocyte activation, as well as cytokine production that can be detected in the serum. ${ }^{18}$ On measuring in vivo cytokine production in F5TCR and F5TCR/OpIAP tg mice $90 \mathrm{~min}$ after antigenic peptide injection, we detected marked differences in IL-2 and IFN- $\gamma$ production. Levels of both cytokines were approximately 10-fold higher in F5TCR/ OplAP tg mouse serum compared to F5TCR littermates (Figure 3c); TNF $\alpha$ concentrations were slightly higher in F5TCR/OpIAP serum compared to those of F5TCR mice (Figure 3c). At $24 \mathrm{~h}$ after antigen peptide injection, we a

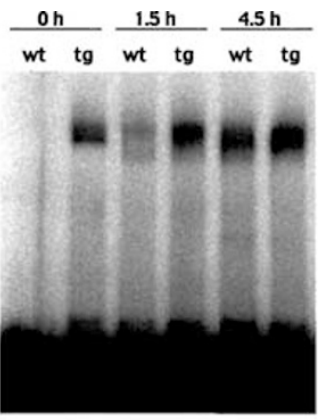

C

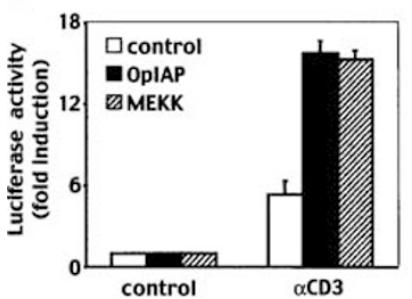

d
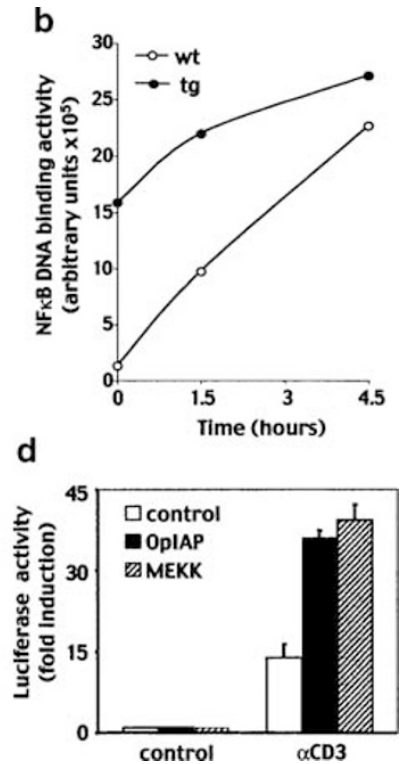

Figure 4 OplAP induces increased NF- $\kappa$ B nuclear translocation and activity. (a) EMSA analysis using lymph node nuclear extracts from F5TCR (wt) and F5TCR/OplAP (tg) mice treated for different times with peptide antigen. (b) NF$\kappa \mathrm{B}$ DNA-binding activity quantified in the lymph node nuclear extracts in panel (a) from F5TCR (wt, open symbols) and F5TCR/OpIAP (closed symbols) mice. Activity is expressed as arbitrary units following phosphoimager quantification. The data show a representative result of three independent experiments. (c) AntiCD3-induced NF- $\kappa$ B activation in Jurkat cells transiently transfected with an empty vector (empty bars) or vectors encoding a MEKK active domain (hatched bars) or OpIAP (filled bars). The bars represent the $x$-fold induction of NF- $\kappa \mathrm{B}$ regulated firefly luciferase activity $14 \mathrm{~h}$ poststimulation, after normalization using a reporter with constitutive Renilla luciferase activity (TK-RL). (d) IL-2 promoter transcription activity in Jurkat cells transfected with an empty vector (empty bars) or vectors encoding a MEKK active motif (hatched bars) or OpIAP (filled bars), after anti-CD3 stimulation. Transcriptional activation is represented as the $x$-fold induction of firefly luciferase activity normalized to Renilla luciferase activity. (c, d) Show results of one experiment, representative of three performed

detected similar T-cell numbers in lymph nodes of F5TCR/ OpIAP compared to F5TCR (Figure 3d); the increased cytokine production detected at early times is thus not associated with increased $\mathrm{tg} \mathrm{T}$-cell survival.

Taken together, these data indicate that OpIAP enhances cytokine production in activated $\mathrm{T}$ lymphocytes following antiCD3 stimulation in culture and, more importantly, after in vivo antigen-triggered activation in the F5TCR model.

\section{OpIAP tg T lymphocytes show higher nuclear NF- $\kappa B$ levels}

NF- $\kappa \mathrm{B}$ transcription factors play an essential role in TCRmediated T-lymphocyte proliferation and activation. ${ }^{19,20}$ Previously, we showed that developing thymocytes from tg mice expressing OpIAP under the Ick promoter have elevated nuclear NF- $\kappa$ B levels. ${ }^{8}$ We examined NF- $\kappa$ B levels in the nuclei of mature OpIAP $\operatorname{tg} T$ lymphocytes, which may explain the increased activation and proliferation responses observed in $\mathrm{tg} \mathrm{T}$ lymphocytes. We performed electrophoretic mobility shift assays (EMSA) using nuclear extracts of in vivo antigenic peptide-triggered lymphocytes from F5TCR and F5TCR/ 
OpIAP mice. Unstimulated F5TCR/OpIAP lymphocytes had high nuclear NF- $\kappa$ B levels, compared to near absence in the nuclei of wt lymphocytes (Figure $4 \mathrm{a}, \mathrm{b}$ ). Antigenic peptide injection induced an increase in nuclear NF- $\kappa \mathrm{B}$ levels in both wt and tg lymphocytes, with a greater increase in wt cells. At $4.5 \mathrm{~h}$ after in vivo peptide challenge, nuclear NF- $\kappa \mathrm{B}$ levels remained higher in tg compared to wt lymphocytes (Figure 4a, b). Taken together, the data indicate that OpIAP expression is associated with high NF- $\kappa$ B DNA-binding activity in resting lymphocytes, which increases after in vivo antigenic peptide challenge.

\section{OpIAP directly induces NF- $\kappa$ B activation in TCR/CD3-triggered T cells}

To further test the effect of OpIAP expression on TCRinduced $\mathrm{NF}-\kappa \mathrm{B}$ activation, we examined $\mathrm{NF}-\kappa \mathrm{B}$ reporter activation in the JHM12 Jurkat T-cell line. These cells were cotransfected with a vector containing OpIAP and another carrying the luciferase gene driven by a promoter element downstream of NF- $\kappa \mathrm{B}$-binding site enhancer elements. As reported, ${ }^{21}$ CD3 triggering induced slight NF- $\kappa$ B activation, which was higher in cells cotransfected with a constitutively active MEKK kinase domain (positive control). MEKK acts as a mediator in the costimulatory pathway in T cells, leading to optimal NF- $\kappa$ B activation. ${ }^{22}$ OpIAP-transfected JHM12 cells showed $\mathrm{NF}-\kappa \mathrm{B}$ reporter activation levels similar to those observed in MEKK-expressing cells (Figure 4c). We also a

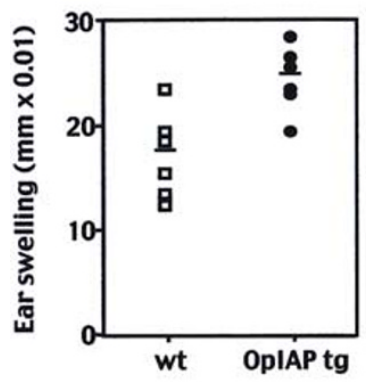

C

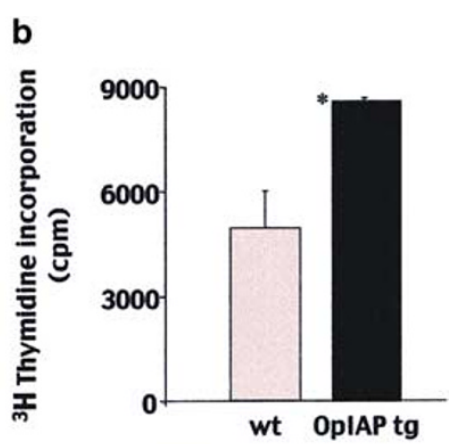

OpIAP tg
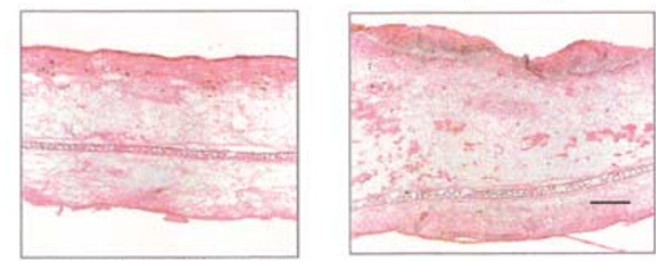

Figure 5 Elevated response of OpIAP tg mice in CHS inflammation. (a) Ear swelling values of wt ( $n=10$, open squares) and OplAP tg mice ( $n=10$, closed circles), $48 \mathrm{~h}$ after DNFB challenge of ears $\left(P=3.5 \times 10^{-5}\right.$, Student's two-tailed $t$-test). (b) ${ }^{3}[H]$ thymidine incorporation of wt ( $n=3$, open symbols) and OpIAP tg lymphocytes ( $n=3$, closed symbols), $48 \mathrm{~h}$ after in vitro DNBS stimulation using $300 \times 10^{3}$ cells per well. The asterisk indicates statistical significance between bars $(P=0.0035$, Student's two-tailed $t$-test). Lymphocytes were obtained from mice 5 days after abdominal DNFB sensitization. (d) Hematoxylin/eosin-stained cryosections of hapten-challenged ears from wt (left panel) and OpIAP tg (right panel) mice at $24 \mathrm{~h}$ postchallenge (magnification, $\times 10$ ) tested NF- $\kappa \mathrm{B}$ transcriptional activity by examining luciferase expression driven by a hIL-2 promoter containing NF- $\kappa \mathrm{B}$ binding sites. Similar to the data obtained with NF- $\kappa$ B-binding site enhancers, the IL-2 promoter-regulated luciferase expression induced after CD3 triggering was higher in OpIAPtransfected JHM12 cells than in control (empty vectortransfected) cells (Figure 4d). Comparable elevated luciferase activity was observed in cells transfected with OpIAP or with MEKK. In contrast, expression of OpIAP or MEKK alone in JHM12 cells did not induce NF- $\kappa$ B activation, which appeared to require CD3/TCR triggering. These results would explain the phenotype of TCR-stimulated OpIAP $\operatorname{tg}$ T lymphocytes, since increased proliferation, CD25 activation marker expression and cytokine production may be directly related to elevated NF- $\kappa$ B activity.

\section{Increased contact hypersensitivity (CHS) response in OpIAP tg mice}

To assess the in vivo effect of the elevated T-lymphocyte activation and proliferative response, we analyzed the $\mathrm{CHS}$ reaction in mice. CHS is a hapten (2,4-dinitrofluorobenzene (DNFB))-induced T-cell response that results in allergic contact dermatitis and inflammation. Epicutaneous application of hapten leads to an oligoclonal T-cell response mediated mainly by $\mathrm{CD}^{+}$cells, whereas $\mathrm{CD} 4^{+}$cells have downregulatory effects at later phases. ${ }^{23}$ We tested whether OplAP expression in T lymphocytes affects the $\mathrm{CHS}$ reaction to DNFB in tg animals. Mice were first sensitized, and the inflammatory response to hapten challenge was then evaluated by measuring ear swelling. At $48 \mathrm{~h}$ postchallenge, OpIAP tg mice showed a clear increase in DNFB-mediated allergic response, as approximately two-fold higher ear swelling values were observed in OpIAP tg mice compared to wt littermates (Figure 5a).

To confirm that the increased CHS response was due to the enhanced $\mathrm{T}$-cell response in the $\mathrm{tg}$ mice, we analyzed the antigen-specific proliferative response of lymphocytes from DNFB-sensitized mice. Lymph node cells were cultured alone or in the presence of 2,4-dinitrobenzene sulfonic acid (DNBS), a water-soluble form of the hapten; after $48 \mathrm{~h}$, cell proliferation was determined by thymidine incorporation. This analysis showed a clear increase in the proliferative response of OpIAP tg compared to that of wt cells (Figure 5b). Lymphocytes from nonsensitized wt and OpIAP tg mice did not proliferate in response to DNBS stimulation (not shown). The antigen-independent proliferative response to PMA and ionomycin showed no differences between wt and OpIAP tg lymphocytes from DNFB-sensitized mice (not shown). Ear lesions were characterized histopathologically, confirming that the elevated inflammation in OpIAP tg animals was associated with greater alteration in dermal tissue (Figure 5c). These data indicate that the increased inflammatory response in OpIAP tg mice to $\mathrm{CHS}$ is due to the elevated antigen-specific T-lymphocyte response.

Taken together, the results indicate that OpIAP enhances tg T-lymphocyte proliferation and activation, reflected as an increased inflammatory response in the $\mathrm{CHS}$ model. 


\section{Discussion}

We analyzed how the expression of an IAP, such as OpIAP, affects T-lymphocyte function and in turn, the T-cell-mediated immune response. Although IAPs are well known for their antiapoptotic function, OpIAP expression in T lymphocytes appears not to affect cell survival during development, since OplAP tg mice have normal cell numbers and T-lymphocyte repertoire in lymph nodes. In addition, survival of in vitro- and in vivo-activated T lymphocytes does not appear to be altered in OpIAP tg mice. The expression of OpIAP in nonstimulated $\operatorname{tg} \mathrm{T}$ lymphocytes leads to a marked increase in NF- $\kappa$ B nuclear levels, similar to that reported for developing OpIAP tg thymocytes. ${ }^{8}$ Moreover, nuclear NF- $\kappa$ B levels in resting OplAP tg lymphocytes were similar to those of wt lymphocytes after in vivo challenge with an antigenic peptide. NF- $\kappa$ B DNAbinding activity nevertheless increased further in $\operatorname{tg} T$ lymphocytes compared to wt after in vivo TCR triggering; these data concur with the OpIAP-mediated increase in NF$\kappa \mathrm{B}$ activity in Jurkat TCR-triggered cells. Although OpIAP expression did not induce NF- $\kappa$ B activation in transfected $T$ cells in the absence of TCR triggering, unstimulated $T$ lymphocytes expressing OpIAP showed elevated nuclear $\mathrm{NF}-\kappa \mathrm{B}$ levels, which were nonetheless insufficient to promote proliferation or activation. This suggests that OpIAP-mediated $\mathrm{NF}-\kappa \mathrm{B}$ nuclear translocation sensitizes $\mathrm{T}$ lymphocytes for greater activation and proliferation in response to TCR/CD3 stimulation. The requirement for TCR/CD3 signals to induce activation and proliferation in OpIAP T lymphocytes suggests that additional NF- $\kappa$ B activation signals are required, and/or that activation of other transcription factors is necessary to integrate the TCR/CD3 signaling pathways in the T lymphocyte.

OpIAP expression in T lymphocytes thus elevates nuclear NF- $\kappa$ B levels, which appear to reinforce the TCR signals, increasing T-cell activation and proliferative response. This idea is supported by data obtained in tg mice expressing a mutant $\mathrm{I} \kappa \mathrm{B} \alpha$ form that cannot be degraded, leading to defective NF- $\kappa$ B activation. In these mice, blockade of NF$\kappa \mathrm{B}$ activation is associated with a defect in CD3-mediated Tlymphocyte activation and proliferation. ${ }^{24,25}$ An increase in NF- $\kappa$ B DNA-binding activity could lead to an opposite phenotype, as we found in OpIAP tg mice. The elevated expression of the CD25 activation marker observed in TCRactivated tg lymphocytes can be explained by $N F-k B$ transcriptional regulation of the CD25 gene. ${ }^{15}$ In addition, the in vitro and in vivo cytokine overproduction described in OpIAP tg T lymphocytes may be due to increased NF- $\kappa$ B DNA-binding activity. This may lead to upregulation of IL-2 and IFN- $\gamma$ genes, which are also targets of this transcription factor. ${ }^{15}$

The mechanism by which OpIAP affects nuclear translocation of $\mathrm{NF}-\kappa \mathrm{B}$ is unknown, although by inducing ubiquitination, OpIAP may induce $\mathrm{I} \kappa \mathrm{B} \alpha$ degradation by the proteosome similar to that described for XIAP in human endothelial cells. ${ }^{7}$ Since the IAP RING motif contains ubiquitin ligase activity in other IAPs, ${ }^{3,26,27}$ we suggest that the OpIAP RING motif has similar activity. OplAP could act in vivo by regulating NF- $\kappa \mathrm{B}$ activity through inducing $I_{\kappa} \mathrm{B} \alpha$ degradation by ubiquitination. Nonetheless, the fact that $I_{\kappa} \mathrm{B} \alpha$ ubiquitination depends on and requires prior phosphorylation ${ }^{28}$ renders this hypothesis unlikely. We therefore speculate on a more probable, ubiquitination-related OpIAP-dependent mechanism that would implicate the IKK kinase complex, which is responsible for $I_{\kappa} \mathrm{B} \alpha$ phosphorylation. A recent study reported the regulation of IKK activity by a kinase that is activated by ubiquination, ${ }^{29}$ demonstrating a mechanism that induces ubiquination-mediated kinase activation rather than degradation. OpIAP-mediated ubiquitination may thus induce kinase activation upstream of IKK, which would in turn activate this complex, leading finally to NF- $\kappa$ B nuclear translocation. A recent report showed that cultured $T$ cells expressing the African swine fever virus IAP homologue induced NF- $\kappa$ B activation, which was associated to elevated IKK activity. ${ }^{9}$ Further studies are required to determine the exact mechanism by which OpIAP induces NF- $\kappa \mathrm{B}$ translocation to the nucleus.

As a result of the in vivo T-lymphocyte activation and proliferation enhancement, OpIAP tg mice developed a severe T-cell-mediated CHS inflammation in which cytokines are crucial for cell activation and migration. ${ }^{23} \mathrm{IFN}-\gamma$ and TNF $\alpha$, which were elevated in OpIAP tg mice after in vivo T-cell activation, are implicated in eliciting the inflammatory response in $\mathrm{CHS}^{23,30}$ Increased cytokine production by OpIAP tg T lymphocytes associated with the increased hapten-induced proliferative response could thus explain the exacerbated $\mathrm{CHS}$ reaction, especially in the inflammatory phase. The elevated nuclear NF- $\kappa$ B levels observed in OpIAP $\operatorname{tg} T$ lymphocytes may explain the increased inflammation observed in CHS, as NF- $\kappa$ B is a key regulator of cellular inflammatory responses. ${ }^{13}$

Our findings indicate that the IAP family member OpIAP affects T-lymphocyte function in vivo. The results constitute the first evidence of IAP involvement in T-cell activation and proliferation associated to increased NF- $\kappa \mathrm{B}$ nuclear presence. This study consequently indicates the importance of IAPs in the immune system, not only in suppressing apoptosis, but also for regulating other cellular processes such as mature T-lymphocyte activation and proliferation. It would be of interest to determine whether the susceptibility to activate, proliferate and produce cytokines by OpIAP tg T lymphocytes leads to the development of autoimmune disease or lymphoproliferative alterations in $t g$ mice.

\section{Materials and Methods}

\section{Mice}

Tg mice expressing OplAP were generated in our laboratory ${ }^{8}$ and were extensively backcrossed to C57BL/6 mice. OplAP cDNA was subcloned into the BamHI site of the $\mathrm{p} 56^{\text {lck }}$ human growth hormone $(\mathrm{hGH})$ vector. A $6.2 \mathrm{~kb}$ Notl fragment containing the Ick proximal promoter OpIAP cDNA and an $\mathrm{hGH}$ sequence were prepared by gel purification and diluted in injection buffer (10 mM Tris pH 7.5, 0.12 mM EDTA). Tg mice were generated by pronuclear microinjection of fertilized oocytes from (C57BL/ $6 \times \mathrm{CBA}) \mathrm{F}_{1}$ mice; microinjected eggs were transferred at the two-cell stage to recipient pseudopregnant OF1 females. Offspring were analyzed by PCR and transgenesis confirmed by Southern blot analysis. For in vivo T-cell activation, we used F5TCR mice (kindly provided by Dr D Kioussis) crossed with OpIAP tg mice to obtain double tg F5TCR/OpIAP tg mice. 


\section{Flow cytometry analysis and cell sorting}

Single-cell suspensions were prepared from control and tg mice by mincing lymph nodes through a $150 \mu \mathrm{m}$ nylon mesh; viable cells were counted by trypan blue exclusion. Lymphocytes were cultured $\left(24 \mathrm{~h}, 37^{\circ} \mathrm{C}\right)$ on plates precoated with anti-CD3 $\varepsilon(2 \mathrm{C} 11)$ antibody (Pharmingen, San Diego, CA, USA) at $5 \mu \mathrm{g} / \mathrm{ml}$, and then stained with saturating antibody concentrations at $4^{\circ} \mathrm{C}$ for flow cytometry analysis. Directly conjugated $\mathrm{mAb}$ were used against CD4-(PE), CD8-(tricolor) and CD25-(FITC) (Pharmingen and Southern Biotechnologies, Birmingham, AL, USA). Flow cytometry and multiparameter analysis were performed on a Coulter Epics $\mathrm{XL}$ cytometer (Coulter, Miami, FL, USA). Dead cells were excluded by gating on forwardand side-light scatter. Anti-CD3-stimulated lymph node cell culture samples were stained with $\mathrm{PI}$ (Coulter DNA-Prep) and cells with apparent DNA content $<2 n$ as determined by flow cytometry analysis were considered apoptotic. Cell suspensions from tg lymph nodes were stained with antiCD3-(FITC) mAb and sorted by FACS (Coulter Epics Altra).

\section{Western blot analysis}

Cytosolic extracts of cell suspensions from total lymph node and $\mathrm{CD} 3^{+}$. sorted $\mathrm{T}$ lymphocytes were prepared by incubation $\left(30 \mathrm{~min}, 4^{\circ} \mathrm{C}\right)$ in extraction buffer ( $50 \mathrm{mM}$ Tris- $\mathrm{HCl}$ pH 7.6, $150 \mathrm{mM} \mathrm{NaCl}, 0.5 \mathrm{mM}$ EDTA, $10 \mathrm{mM} \mathrm{NaH}_{2} \mathrm{PO}_{4}, 1 \%$ Nonidet-P40, $0.4 \mathrm{mM} \mathrm{Na}_{3} \mathrm{VO}_{4}, 1 \mathrm{mM} \mathrm{PMSF}, 10 \mu \mathrm{g} /$ $\mathrm{ml}$ aprotinin and $10 \mu \mathrm{g} / \mathrm{ml}$ leupeptin). Cell lysates were centrifuged to deplete nuclei. Cytosolic extracts (30 $\mu \mathrm{g} / \mathrm{lane}$ ) were resolved in 10\% SDSPAGE and transferred to nitrocellulose membranes (Bio-Rad, Hercules, CA, USA). Western blot was performed using rabbit anti-OpIAP serum and developed with horseradish peroxidase (HRP)-conjugated anti-rabbit IgG antibody (Dako, Glostrup, Denmark; $1: 1000$ dilution). Anti-mouse $\beta$-actin Ab (Sigma, St. Louis, MO, USA), developed with HRP-conjugated antimouse IgG antibody (Dako), was used to confirm protein loading.

\section{Proliferation assays}

Lymphocytes were cultured in complete medium (RPMI 1640 with $10 \%$ fetal calf serum, $10 \mu \mathrm{M}$ mercaptoethanol, $100 \mathrm{mM}$ L-glutamine, $10 \mathrm{mM}$ HEPES and antibiotics), then plated $\left(4 \times 10^{5}\right.$ cells/well) in 96-well flatbottom microtiter plates precoated overnight with PBS or anti-CD3 $\varepsilon$ antibody at $5 \mu \mathrm{g} / \mathrm{ml}$ or at suboptimal doses (Figure 2). Antigen-induced lymphocyte proliferation was triggered using DNBS ( $50 \mu \mathrm{g} / \mathrm{ml}$; Sigma) in cultures of lymphocytes from wt and OpIAP tg mice, 5 days after DNFB sensitization. Stimulation was also induced in the presence of PMA (10 ng/ $\mathrm{ml})$ plus ionomycin $(1 \mu \mathrm{g} / \mathrm{ml})$. Triplicate samples were cultured $(48 \mathrm{~h}$, $\left.37^{\circ} \mathrm{C}\right)$ for all assays. ${ }^{3}[\mathrm{H}$ ]thymidine $(1 \mu \mathrm{Ci} /$ well $)$ was added, cells harvested $8 \mathrm{~h}$ later and radioisotope incorporation into DNA determined.

\section{ELISA assays}

In vitro IL-2, IFN- $\gamma$ and TNF $\alpha$ production were measured in ELISA in culture supernatants from $T$ lymphocytes, unstimulated or stimulated with anti-CD3 $(1 \mu \mathrm{g} / \mathrm{ml})$, on plates precoated with anti-mouse antibodies (IL-2 and IFN- $\gamma$, Endogen, Boston, MA, USA; TNF $\alpha$, R\&D Systems, Minneapolis, MN, USA). Quantification was by comparison to standards supplied. In vivo cytokine production was measured from mouse serum $90 \mathrm{~min}$ after antigenic peptide injection. ELISA was performed as described above.

\section{Nuclear protein extraction and EMSA}

To obtain nuclear extracts, T lymphocytes from control (PBS) and F5 antigen peptide-injected mice were incubated $\left(10 \mathrm{~min}, 4^{\circ} \mathrm{C}\right)$ in buffer $A$
(10 mM HEPES pH 7.6, $10 \mathrm{mM} \mathrm{KCl,} 0.1 \mathrm{mM}$ EDTA, $0.1 \mathrm{mM}$ EGTA, 1\% NP40) before centrifugation to pellet nuclei. Nuclei were lysed by incubation ( $30 \mathrm{~min}, 4^{\circ} \mathrm{C}$, with agitation) in buffer $\mathrm{B}(20 \mathrm{mM} \mathrm{HEPES} \mathrm{pH} 7.6$, $20 \%$ glycerine, $420 \mathrm{mM} \mathrm{NaCl}, 1.5 \mathrm{mM} \mathrm{MgCl}_{2}, 0.2 \mathrm{mM}$ EDTA). After centrifugation, supernatants containing nuclear proteins were separated and frozen at $-70^{\circ} \mathrm{C}$. EMSA was performed using a ${ }^{32} \mathrm{P}$-labeled, doublestranded oligonucleotide bearing the human IL-2 promoter $\kappa \mathrm{B}$ site $\left(5^{\prime}\right.$ GATCGGGATTTCACCT-3'). DNA-binding reactions (12.5 $\mu$ l) containing $5 \mu \mathrm{g}$ nuclear extracts, $2 \mu \mathrm{g}$ poly (dl-dC) and $2.5 \mathrm{mM}$ EDTA, $2.5 \mathrm{mM}$ DTT, $2.5 \%$ glycerol in $50 \mathrm{mM}$ Tris $(\mathrm{pH} 8)$ were incubated $\left(10 \mathrm{~min}, 4^{\circ} \mathrm{C}\right) ; 10^{5} \mathrm{cpm}$ of radiolabeled oligonucleotide probe were added and incubated ( $30 \mathrm{~min}$, $4{ }^{\circ} \mathrm{C}$ ). The resulting nucleoprotein complexes were resolved by electrophoresis in native $4 \%$ polyacrylamide gels (in $0.5 \times$ TBE; $120 \mathrm{~V}, 2.5 \mathrm{~h}$ ), then visualized and quantified by phosphoimaging (Molecular Dynamics, Sunnyvale, CA, USA). The background was subtracted using the local median algorithm of the ImageQuant program (v.1.2. Molecular Dynamics).

\section{Luciferase assay}

JHM12 cells were transiently cotransfected with the Renilla luciferase vector $\mathrm{pRL}-\mathrm{TK}$, an inducible vector containing the luciferase reporter gene, and (i) pEF-Bos (pEF) vector (control), (ii) pEF bearing the OpIAP sequence, or (iii) the pFC active MEKK1 domain (positive control). The reporter gene was under the control of a basic promoter with NF- $\kappa \mathrm{B}$ binding sites bearing enhancer elements, or of the hlL-2 promoter, which contains NF- $\kappa$ B-binding domains (PathDetect NF- $\kappa$ B cis-Reporting System; Stratagene, La Jolla, CA, USA). At $48 \mathrm{~h}$ post-transfection, cells were cultured for $14 \mathrm{~h}$ in anti-CD3-coated plates and a luciferase assay was performed. Luciferase inducible activity was normalized using the Renilla luciferase constitutive activity in transfected cells.

\section{CHS assay and immunohistochemistry}

Mice were sensitized by topical application of $50 \mu \mathrm{l}$ DNFB (0.25\%; Sigma) in acetone/olive oil $(4: 1)$ to the shaved abdomen. After 5 days, $10 \mu \mathrm{l}$ of $0.2 \%$ DNFB in the same solution was applied to both sides of the right ear and solvent alone (control) to the left ear. Ear thickness was measured with a micrometer (Mitutoyo Corp., Kawasaki, Japan) before challenge and each day after challenge. Ear swelling was determined by subtracting pre- from postchallenge values and any swelling detected in the challenged control ear. For histopathological analyses, treated ears were frozen to prepare ear sections $(10 \mu \mathrm{m})$, which were then hematoxylin/ eosin stained and examined by light microscopy.

\section{Acknowledgements}

We thank Dr D Kioussis (MRC, London, UK) for kindly providing F5 TCR mice, Drs A Brás and R Varona for technical assistance, Dr M SchmidtSupprian for critical reading of the manuscript, Dr JA Garcia-Sanz for experimental and manuscript review, Dr E Jambrina for luciferase assays, L Gómez and D García for mouse work and C Mark for editorial assistance. MS Robles received fellowships from the CSIC/Pharmacia and the Regional Government of Madrid (CAM). This work was supported by grants from the Dirección General de Investigación, Ministry of Science and Technology. The Department of Immunology and Oncology was founded and is supported by the Spanish Council for Scientific Research (CSIC) and by Pfizer. 


\section{References}

1. Deveraux QL and Reed JC (1999) IAP family proteins - suppressors of apoptosis. Genes Dev. 13: 239-252

2. Salvesen GS and Duckett CS (2002) IAP proteins: blocking the road to death's door. Nat. Rev. Mol. Cell. Biol. 3: 401-410

3. Joazeiro CA and Weissman AM (2000) RING finger proteins: mediators of ubiquitin ligase activity. Cell 102: 549-552

4. Yang Y, Fang S, Jensen JP, Weissman AM and Ashwell JD (2000) Ubiquitin protein ligase activity of IAPs and their degradation in proteasomes in response to apoptotic stimuli. Science 288: 874-877

5. Hauser HP, Bardroff M, Pyrowolakis G and Jentsch S (1998) A giant ubiquitinconjugating enzyme related to IAP apoptosis inhibitors. J. Cell. Biol. 141: 14151422

6. Hofer-Warbinek R, Schmid JA, Stehlik C, Binder BR, Lipp J and de Martin R (2000) Activation of NF- $\kappa$ B by XIAP, the X chromosome-linked inhibitor of apoptosis, in endothelial cells involves TAK1. J. Biol. Chem. 275: 22064-22068

7. Levkau B, Garton KJ, Ferri N, Kloke K, Nofer JR, Baba HA, Raines EW and Breithardt G (2001) XIAP induces cell-cycle arrest and activates NF- $\kappa B$ : new survival pathways disabled by caspase-mediated cleavage during apoptosis of human endothelial cells. Circ. Res. 88: 282-290

8. Robles MS, Leonardo E, Criado LM, Izquierdo M and Martinez-A C (2002) Inhibitor of apoptosis protein from Orgyia pseudotsugata nuclear polyhedrosis virus provides a costimulatory signal required for optimal proliferation of developing thymocytes. J. Immunol. 168: 1770-1779

9. Rodriguez $\mathrm{CI}$, Nogal ML, Carrascosa AL, Salas ML, Fresno M and Revilla Y (2002) African swine fever virus IAP-like protein induces the activation of NF$\kappa$ B. J. Virol. 76: 3936-3942

10. Wang CY, Mayo MW, Korneluk RG, Goeddel DV and Baldwin Jr AS (1998) NF$\kappa \mathrm{B}$ antiapoptosis: induction of TRAF1 and TRAF2 and C-IAP1 and c-IAP2 to suppress caspase-8 activation. Science 281: 1680-1683

11. Huang Q, Deveraux QL, Maeda S, Salvesen GS, Stennicke HR, Hammock BD and Reed JC (2000) Evolutionary conservation of apoptosis mechanisms: lepidopteran and baculoviral inhibitor of apoptosis proteins are inhibitors of mammalian caspase-9. Proc. Natl. Acad. Sci. USA 97: 1427-1432

12. Hawkins CJ, Ekert PG, Uren AG, Holmgreen SP and Vaux DL (1998) Antiapoptotic potential of insect cellular and viral IAPs in mammalian cells. Cell Death Differ. 5: 569-576

13. Ghosh S and Karin M (2002) Missing pieces in the NF- $\kappa$ B puzzle. Cell 109 (Suppl.): S81-S96

14. Silverman $N$ and Maniatis $T$ (2001) NF- $\kappa B$ signaling pathways in mammalian and insect innate immunity. Genes Dev. 15: 2321-2342

15. Pahl HL (1999) Activators and target genes of Rel/NF- $\kappa B$ transcription factors. Oncogene 18: 6853-6566

16. Chen CL, Singh N, Yull FE, Strayhorn D, Van Kaer L and Kerr LD (2000) Lymphocytes lacking $I_{\kappa} \mathrm{B} \alpha$ develop normally, but have selective defects in proliferation and function. J. Immunol. 165: 5418-5127
17. Mamalaki C, Elliott J, Norton T, Yannoutsos N, Townsend AR, Chandler $P$, Simpson E and Kioussis D (1993) Positive and negative selection in transgenic mice expressing a T-cell receptor specific for influenza nucleoprotein and endogenous superantigen. Dev. Immunol. 3: 159-174

18. Mamalaki C, Norton T, Takana Y, Townsend AR, Chandler P, Simpson E and Kioussis D (1992) Thymic depletion and peripheral activation of class I major histocompatibility complex-restricted T cells by soluble peptide in T cell receptor transgenic mice. Proc. Natl. Acad. Sci. USA 89: 11342-11346

19. Sha WC (1998) Regulation of immune responses by NF- $\kappa$ B/Rel transcription factor. J. Exp. Med. 187: 143-146

20. Aronica MA, Mora AL, Mitchell DB, Finn PW, Johnson JE, Sheller JR and Boothby MR (1999) Preferential role for NF- $\kappa$ B/Rel signaling in the type 1 but not type 2T cell-dependent immune response in vivo. J. Immunol. 163: 51165124

21. Lin X, O'Mahony A, Mu Y, Geleziunas R and Greene WC (2000) Protein kinase C-theta participates in NF- $\kappa$ B activation induced by CD3-CD28 costimulation through selective activation of $\mid \kappa B$ kinase beta. Mol. Cell. Biol. 20: 2933-2940

22. Tuosto L, Costazo A, Guido F, Marinari B, Vossio S, Moretti F, Levrero M and Piccolella E (2000) Mitogen-activated kinase kinase kinase 1 regulates T cell receptor- and CD28-mediated signaling events which lead to NF- $\kappa$ B activation. Eur. J. Immunol. 30: 2445-2454

23. Grabbe S and Schwarz T (1998) Immunoregulatory mechanisms involved in elicitation of allergic contact hypersensitivity. Immunol. Today 19: 37-44

24. Boothby MR, Mora AL, Scherer DC, Brockman JA and Ballard DW (1997) Perturbation of the $T$ lymphocyte lineage in transgenic mice expressing a constitutive repressor of NF- $\kappa$ B. J. Exp. Med. 185: 1897-1907

25. Ferreira V, Sidenius N, Tarantino N, Hubert $P$, Chatenoud L, Blasi F and Korner M (1999) In vivo inhibition of NF- $\kappa B$ in T-lineage cells leads to a dramatic decrease in cell proliferation and cytokine production and to increased cell apoptosis in response to mitogenic stimuli, but not to abnormal thymopoiesis. J. Immunol. 162: 6442-6450

26. Huang $\mathrm{H}$, Joazeiro $\mathrm{CA}$, Bonfoco $\mathrm{E}$, Kamada S, Leverson JD and Hunter $\mathrm{T}$ (2000) The inhibitor of apoptosis, clAP2, functions as a ubiquitin-protein ligase and promotes in vitro monoubiquitination of caspases 3 and 7 . J. Biol. Chem. 275: 26661-26664

27. Suzuki $Y$, Nakabayashi $Y$ and Takahashi $R$ (2001) Ubiquitin-protein ligase activity of X-linked inhibitor of apoptosis protein promotes proteasomal degradation of caspase-3 and enhances its anti-apoptotic effect in Fas-induced cell death. Proc. Natl. Acad. Sci. USA 98: 8662-8667

28. Karin M (1999) How NF- $\kappa$ B is activated: the role of the $I_{\kappa} \mathrm{B}$ kinase (IKK) complex. Oncogene 18: 6867-6874

29. Wang C, Deng L, Hong M, Akkaraju GR, Inoue J and Chen ZJ (2001) TAK1 is a ubiquitin-dependent kinase of MKK and IKK. Nature 412: 346-351

30. Kehren J, Desvignes C, Krasteva M, Ducluzeau MT, Assossou O, Horand F, Kagi D, Kaiserlian D and Nicolas JF (1999) Cytotoxicity is mandatory for CD8(+) T cell-mediated contact hypersensitivity. J. Exp. Med. 189: 779-786 